\title{
A mudança estrutural do Público e do Privado
}

\section{The Structural Transformation of the Public and Private}

\author{
Hélder Prior*, João Carlos Sousa** \\ *Online Communication Lab (LabCom) - Universidade da Beira Interior, Rua Marquês D'Ávila e Bolama 6201-001 Covilhã. \\ Observatorio Iberoamericano de la Comunicación - Autonomous University of Barcelona (helder.prior@gmail.com) \\ **Online Communication Lab (LabCom). Universidade da Beira Interior, Rua Marquês D'Ávila e Bolama 6201-001 Covilhã. \\ (joao.sousa@labcom.ubi.pt)
}

Resumo

\begin{abstract}
Neste ensaio procuraremos delinear uma espécie de genealogia do binómio público/privado identificando, num primeiro momento, os principais sentidos históricos de uma dicotomia secular para, em seguida, nos debruçarmos sobre a irrupção do espaço privado por excelência. Na terceira e última parte, prestaremos especial atenção à democratização da intimidade sem, no entanto, esquecer a forma como a progressiva mediatização da sociedade contribui para a confusão entre as experiências públicas e as experiências privadas.
\end{abstract}

Palavras-chave: Público, Privado, Intimidade

Abstract

In this essay we will try to delineate a kind of genealogy of public and private binomial identifying, first of all, the historical sense of a secular dichotomy, then turning to the eruption of the private space par excellence. In the third and last part, we will pay special attention to the democratization of intimacy without, however, forgetting how progressive mediatisation of society contributes to the confusion between public and private experiences.

Keywords: Public, Private, Intimacy

\section{Um debate secular}

Talvez não seja de todo despropositado iniciar esta reflexão partindo do pressuposto de que, na contemporaneidade, o debate sobre o público e o privado readquiriu uma certa densidade epistemológica, política, jurídica e social. Epistemológica porque enfrentamos a necessidade de melhor compreender as noções

Copyright (C) 2014 (Hélder Prior and João Carlos Sousa). Licensed under the Creative Commons Attribution Non-commercial No Derivatives (by-nc-nd). Available at http://obs.obercom.pt. 
de público e de privado na actualidade tendo em conta o conteúdo conferido a cada conceito ao longo dos tempos; política e jurídica porque não é possível estudar a vida privada sem ter em conta a margem de autonomia que the é deixada pelo poder político e pela doutrina jurídica; social porque as variações do binómio público/privado só podem ser empreendidas avaliando os comportamentos dos homens, as regras que estes impõem a si próprios, ou que Ihes são impostas pelos hábitos das comunidades onde vivem, bem como as práticas quotidianas que, naturalmente, variam segundo a pessoa, os lugares e os tempos. É certo que traçar as fronteiras entre o público e o privado tem sido uma preocupação desde a antiguidade clássica, facto que revela um horizonte de discussão bastante amplo em termos históricos. Porém, o facto de a relação público/privado consistir num debate secular não significa que se tenha chegado a definições consensuais acerca daquilo que está contido em cada uma das esferas, até porque, como já referimos, os conceitos apresentam uma variabilidade explicada por fenómenos políticos, culturais e até jurídicos. 0 binómio público/privado acabou por se converter numa "grande dicotomia", com várias categorias de sentido, que tem despertado o interesse das disciplinas jurídicas, históricas e políticas, mas também das Ciências Sociais, uma vez que as noções de público e privado têm funcionado, ao longo dos tempos, como componentes estruturantes do mundo simbólico. Genericamente, podemos falar de uma grande dicotomia quando nos encontramos perante a possibilidade de dividir um universo em duas esferas "conjuntamente exaustivas" e "reciprocamente exclusivas". Conjuntamente exaustivas no sentido de que todos os entes pertencentes a uma determinada esfera nela tenham lugar; reciprocamente exclusivas na medida em que um ente compreendido na primeira não pode ser, simultaneamente, compreendido na segunda. De outro modo, um dos lugarescomuns do debate sobre o público e o privado consiste em afirmar que cada esfera se define em contraste com a outra, surgindo o privado muitas vezes definido como "não-público", e que aumentando a esfera do público diminui a do privado e aumentando a do privado diminui a do público (Bobbio, 2009: 13-14).

Do ponto de vista genealógico, talvez tenha sido a civilização helénica aquela que melhor demarcou o público, enquanto esfera da política por excelência e governo da cidade, do privado, do domínio da casa e dos processos biológicos da vida e da morte próprios do reino da necessidade. No Espaço Público Clássico, o privado é um lugar oposto e que existe separadamente face ao público, sendo este o domínio por excelência da liberdade e da organização política. Na Esfera Pública Ateniense, o Senhor eleva-se à condição de cidadão, de zoon politikon, saindo do reino pré-político da necessidade, da dominação e dos processos biológicos. Com efeito, privadas eram as coisas que não diziam respeito à comunidade e que, por isso mesmo, não deveriam ser partilhadas, desveladas, acessíveis a olhares alheios. 0 privado encerra uma dimensão de domesticidade, mas também da reserva e ocultamento próprias da esfera da casa (oikia), enquanto o público denota o comum, mas também a visibilidade e a aparência do homem enquanto animal político no espaço público da agora (Cf. Carvalheiro, Prior, Morais, 2013).

Esta concepção helenística de público e privado foi herdada pela civilização romana, mas apesar da distinção entre público e privado continuar a servir de quadro à organização política do Espaço Público do fórum, os 
conceitos sofreram o enfoque do Direito romano consagrando-se a distinção entre publicus - quod ad statum rei romanae spectat -, coincidindo o público com o domínio do Estado, e privatus - quod ad singulorum utilitatem -, apontando o privado para aquilo que se refere ao indivíduo singular. Durante a Idade Média esta oposição permitiu regular a ordem feudal, mas o conceito de público revestiu-se de uma nova configuração. Efectivamente, os textos medievais associam o conceito de público aos espaços que escapam à apropriação exclusiva ou privada, passando este a compreender os caminhos, as ruas, as praças, os rios e alguns equipamentos e infra-estruturas. É, precisamente, no contexto da ordem medieval que surge a ideia de comunidade e de espaços públicos comuns que podem ser livremente utilizados por essa mesma comunidade (Cf. Rodrigues, s/d). Como se sabe, o binómio público/privado constitui-se como um fenómeno de fronteiras difusas e ambíguas, fronteiras que, de resto, têm sido sucessivamente alteradas por uma variabilidade histórica que importa analisar. Durante o período do Absolutismo Régio foi, precisamente, a distinção público não público que fundamentou e legitimou a doutrina política da razão de Estado. No contexto político do desenvolvimento do Estado moderno, a prática racional de governação contempla o recurso aos arcana imperii, aos segredos de Estado, ao carácter oculto de máximas de governação que não devem ser tornadas públicas por dizerem respeito à conservação do Estado, aos jus defensionis e à salus rei publicae (Meinecke, 1983, Senellart, 1995, Zarka, 1994). Historicamente não se deve, portanto, confundir a distinção público/privado, no sentido da "grande dicotomia" que temos vindo a analisar, com a distinção público/secreto, poder visível/poder invisível. Do ponto de vista conceptual, o carácter público do poder, no qual por público se entende aquilo que acontece à vista do Público, algo que é, portanto, manifesto, aberto, visível, por oposição ao secreto, é um problema diferente daquele que se refere à esfera de competência do poder político distinto do poder dos privados. Com efeito, o poder político é o poder público no sentido da grande dicotomia mesmo quando não é público, não age em público, subtrai-se do publicum e não é controlado por este. Foi Immanuel Kant quem expôs com clareza o problema do carácter público do poder, contrariando o princípio da publicidade à teoria dos arcana imperii dominante na época do poder absoluto. Ao arcanum do poder autocrático, a filosofia do Iluminismo responde com a exigência da publicidade enquanto princípio apodíctico e fórmula transcendental do direito público. Kant sustenta que a única forma de garantir à actividade política uma justificação ética é a condenação do segredo nos actos do governo sendo "injustas todas as acções que se referem ao direito de outros homens cujas máximas não se harmonizem com a publicidade" (Kant, 2004: 165).

Deste modo, e como com acerto constata Niklas Luhmann na obra onde versa sobre $A$ Improbabilidade da Comunicação, só no século XVIII se reuniram as duas distinções, a de público/privado e a de público/secreto, sendo que só na parte final deste século surgiu o conceito moderno de opinião pública como soberano secreto e autoridade invisível da sociedade política (Luhmann, 1992: 65-66). Trata-se de um publicum constituído por pessoas privadas que procuram obrigar o poder público (estatal) a legitimar-se perante o tribunal da opinião pública. Na esfera pública burguesa o público converteu-se numa instância de decisão que procura defender 
os interesses privados dos cidadãos face à autoridade do Estado. A esfera pública que, outrora, tinha sido considerada uma esfera do poder público, separa-se deste e converte-se num novo fórum onde as pessoas privadas, reunidas em qualidade de público, levam a cabo um processo de "auto-ilustração", de exercício da racionalidade e de gouvernement by discussion. Este conceito de esfera pública, tal como emergiu no espírito da Ilustração do século XVIII, alude à ideia de um espaço de acção onde os membros de uma comunidade fazem uso público da razão, convertendo o conflito em debate e problematizando os assuntos de interesse comum. A Esfera Pública burguesa, enquanto espaço de sociabilidade constituído por pessoas privadas que reclamam uma esfera regulada à margem da autoridade pública do Estado, viu nascer a instância do Público sujeito, uma entidade crítica que só através do uso público da razão consegue publicidade (Öffentlichkeit). Mas a nova esfera pública não diferenciou, apenas, o Estado da sociedade. A esfera privada também sofreu transformações, nomeadamente aquelas que resultam da diferenciação entre economia (mercado) e família enquanto "esfera íntima" e, portanto, enquanto lugar mais privado de todos (Habermas, 2012). É neste processo de desenvolvimento da modernidade que vemos surgir um novo quadro de privatização da vida. No século XVIII surge uma alteração no estilo arquitectónico do lar burguês que reserva cada vez mais importância à esfera íntima da família nuclear, isto é, à subjectividade e intimidade próprias dos seus membros. As casas construídas de raiz oferecem mais espaço às divisões destinadas à salvaguarda da intimidade na vida doméstica. Desenvolve-se, assim, o gosto pelo espaço privado edificando-se o salão como linha divisória entre a esfera privada e a esfera pública. As pessoas privadas saem da intimidade dos quartos para se projectarem no espaço institucional do salão que, por sua vez, representa o lugar de emancipação económico-política. $\mathrm{O}$ publicum constituído por pessoas privadas que procuram o esclarecimento mediante 0 raciocínio publicamente partilhado provém da subjectividade do espaço do lar. As alterações arquitectónicas nas casas construídas de raiz são o reflexo da nova privatização da vida. A divisão comum para o homem, a mulher, os filhos e a criadagem tornou-se cada vez mais pequena surgindo, em contrapartida, o quarto específico de cada membro da família burguesa. Efectivamente, foram os burgueses dos séculos XVIII e XIX que defenderam, com toda a força, o espaço privado inscrito no interior da casa, reduto de subjectividade e introspecção onde os indivíduos se vêem a si próprios como seres independentes, esfera de humanidade do relacionamento íntimo de seres humanos.

\section{A irrupção do Privado}

Derivado do latim privatus, que significa "despojar" ou "tirar", pode dizer-se que o termo "privado" está vinculado ao direito de os indivíduos guardarem para si próprios o controlo de determinadas informações, isto é, a possibilidade de se manterem protegidos e à parte de qualquer conhecimento público dos seus actos. A esfera privada compreende aqueles comportamentos, acontecimentos e condutas que os indivíduos desejam 
que não se tornem do domínio público e que, portanto, não estão à vista da colectividade em geral nem de um círculo indeterminado de pessoas. A esfera privada refere-se, com efeito, ao indivíduo escudado na intimidade ou no recato, um espaço de convívio com a própria individualidade sem a perturbação da publicidade e da intromissão alheia. De facto, o espaço privado é uma área particular reservada ao refúgio e ao recolhimento, uma zona delimitada de imunidade e negligência onde cada indivíduo pode repousar as armas com as quais é conveniente estar provido quando se apresenta na esfera pública. Do ponto de vista histórico, Phillippe Ariès e Georges Duby foram os precursores que abriram as primeiras brechas na exploração de um espaço tão vasto. Segundo Duby, "no privado encontra-se guardado o que se possui de mais precioso, que só a nós pertence, que não diz respeito a mais ninguém, que é proibido divulgar, mostrar, porque é muito diferente das aparências que a honra exige salvar em público" (Ariès e Duby, 1989: 10).

Para os gregos a esfera privada (to idion) manifestava a qualidade daquilo que, por não dizer respeito à comunidade, não deveria ser partilhado. É por isso que a sua original acepção é a de "privação", privação do contacto com os outros e do relacionamento do indivíduo com os seus semelhantes. Como constata Hannah Arendt, "para o indivíduo, viver uma vida inteiramente privada significa, acima de tudo, ser destituído de coisas essenciais à vida verdadeiramente humana: ser privado da realidade que advém do facto de ser visto e ouvido por outros, privado de uma relação objectiva com eles, decorrente do facto de se ligar e separar deles através de um mundo comum de coisas, e privado da possibilidade de realizar algo mais permanente que a própria vida" (Arendt, 2001: 74). Com efeito, nas circunstâncias da antiga cidade-estado, a distinção entre uma esfera da vida pública e uma esfera da vida privada corresponde à existência das esferas da polis e da família como entidades inerentes ao mundo comum e à manutenção da vida, respectivamente. Segundo o pensamento dos antigos, os assuntos relacionados com a sobrevivência do indivíduo e da sua família não eram assuntos políticos, mas domésticos, privados, inerentes à organização familiar, uma organização completamente diferente da polis.

No interior da esfera privada, o labor é a actividade que assegura a sobrevivência do indivíduo, uma actividade que tem que ver com as necessidades vitais de preservação da espécie humana e que remete para os processos biológicos e para os imperativos de sobrevivência do animal laborans. Na esfera da família, os homens eram impelidos a viver em comunhão devido às necessidades e carências inerentes à própria vida. A sobrevivência da espécie requeria a companhia de outros. Por conseguinte, o labor do homem na obtenção de alimentos para o sustento da família, e o labor da mulher no parto na sobrevivência da espécie, eram funções naturais do lar que decorriam da necessidade e da premência da vida (Idem: 45). O labor é, assim, uma actividade própria de um espaço privado cujo centro é constituído pela casa (oikia) e pela família. Designa uma das três actividades fundamentais da condição humana enraizadas na vita activa. As outras duas são o trabalho (work) e a acção. Segundo Arendt, o trabalho é a actividade correspondente ao "artificialismo" e à intervenção da espécie humana na natureza. O trabalho produz um mundo "artificial" de coisas (Idem: 19) e a sua condição é a da mundanidade. Distintamente do animal laborans que se insere no ciclo vital da espécie 
humana, da animalidade e necessidade de sobrevivência, o homo faber actua sobre a materialidade das coisas para produzir um mundo artificial. É, portanto, uma actividade especificamente humana na medida em que se refere a uma dimensão fabricadora de mundanidade onde o homem actua directamente sobre a natureza, condicionando as coisas naturais e criando as condições físicas para que o homem possa "viver" e "estar" entre os homens (inter homines esse). Enquanto o labor pertence ao domínio da necessidade e à esfera privada, o trabalho é inerente à criação de um mundo social e gregário. Ele fornece os elementos físicos e materiais para a condição humana da pluralidade, isto é, para a terceira actividade humana fundamental, o envolvimento do homem na política. A acção é, assim, uma condição humana eminentemente pública que remete para a alteridade, para a pluralidade e para a construção de um modo de vida político na polis. A acção é a única actividade que se exerce directamente entre os homens sendo a pluralidade não apenas a conditio sine qua non, mas também a condition per quam de toda a vida política (Idem: 10). A raison d'être da acção resulta da "comparticipação de palavras e actos" (Idem: 248) no espaço público através da publicidade discursiva. É por isso que a polis é a organização da comunidade resultante do agir e do falar de pessoas em comunhão que assumem uma aparência explícita. O espaço público clássico é uma esfera de epiphaneia, um espaço onde os indivíduos aparecem uns perante os outros, palco de visibilidade, de figuração e aparição, por oposição ao anonimato, ao ocultamento e à ausência de aparição do indivíduo perante os seus pares que caracteriza o carácter privativo da esfera privada. $\mathrm{Na}$ antiga cidade-estado, a esfera privada era um lugar de invisibilidade e de não aparição, uma esfera onde o indivíduo se encontrava privado de uma relação objectiva com os outros que não passasse pela mera sobrevivência da espécie. O homem privado não se dá a conhecer, não se apresenta perante os seus pares, não se torna visível, não exibe a sua aparência no espaço público: "o que quer que ele faça permanece sem importância ou consequência para os outros, e o que tem importância para ele é desprovido de interesse para os outros" (Idem: 74). Com efeito, na civilização helénica a esfera pública e a esfera privada constituem-se como esferas antitéticas e apartadas que existem separadamente. 0 público como governo da cidade e domínio de liberdade onde o indivíduo exerce a sua condição de cidadão, e o privado definido como domínio da casa onde o indivíduo se rege pelas leis inerentes ao reino da necessidade, à dominação sobre as mulheres, as crianças e os escravos, e aos processos biológicos da vida e da morte.

Como vemos, os gregos entendiam as esferas pública e privada como entidades autónomas e definidas em completa oposição, sacrificando o privado em benefício do público. A esfera privada assumia-se negativamente como a esfera do ocultamento onde os indivíduos viviam uma existência incerta e obscura, em contraste com o mundo comum da esfera pública caracterizado pela reunião dos indivíduos na companhia uns dos outros. Efectivamente, foram os romanos, pelo contrário, que compreenderam que as esferas pública e privada só poderiam subsistir sob a forma de coexistência (Arendt, 2001: 74). A casa dos romanos, desde sempre designada pelos termos gregos, oikos ou grupo humano residente, e oikia ou edifício que o abriga, surge como charneira dos dois domínios, espaço não inteiramente privado que, em certos casos, se insere no domínio 
público. Nas aldeias, as chamadas "assembleias dos chefes de casa" assumiam as responsabilidades judiciais e fiscais da comunidade rural. Por outro lado, o núcleo do oikos aristocrático, apesar de ser constituído por parentes, engloba, também, familiares (oikeiol), "servidores" (okêtol), e outros homens (anthrôpol) e amigos (philol) que agiam na cena política do palácio. Segundo Ariès e Duby, "um tal oikos é um espaço ambivalente na medida em que, colocado na antípoda do palácio, coração político do Império, tanto serve de base ao empreendimento público como ao recolhimento. Esta ambivalência estende-se às residências provinciais das grandes famílias, que a todo o momento podem adquirir um significado político" (Ariès, Duby, 1989: 547).

Os romanos colocavam o aparecimento da casa não apenas no quadro das necessidades individuais, mas num quadro inserido no contexto societal. A casa romana era caracterizada por graus diferenciados de opacidade, assumindo-se como local de actividades que nos dias de hoje parecem ser de âmbito público. O senhor da casa recebia, frequentemente, visitas do vasto círculo dos seus clientes, facto que levou o arquitecto romano Vitrúvio a utilizar a expressão "locais públicos" para designar as partes das residências abertas às pessoas oriundas do exterior. Tais espaços não se constituíam como domínios essencialmente privados ou essencialmente públicos, mas antes como o reflexo de um tipo de sociedade que manifestava uma articulação entre o privado e o público. "Da mesma forma que a vida no seio de uma casa conhece toda uma gama de modalidades, do isolamento individual à recepção de um grande número de pessoas com as quais o proprietário pode não manter qualquer tipo de ralação íntima, assim os espaços da residência são caracterizados por um grau de opacidade muito variável relativamente ao mundo exterior" (Idem: 339). As casas dos notáveis do Império, por exemplo, acolhiam várias circunstâncias de vida privada, compreendendo espaços de retiro individual e partes residenciais destinadas à família no sentido estrito do termo. Por outro lado, quer no tempo da grandeza de Roma, quer no tempo do seu declínio, os romanos distinguiam muito mal funções públicas e dignidade privada, finanças públicas e bolsa pessoal, sendo possível identificar numerosas redes de clientelismo político onde as funções públicas eram tratadas como dignidades privadas (Cf. Ariès, Duby, 1989: 103-105).

Como vemos, a natureza do espaço privado é característica de cada sociedade e das relações que nela se estabelecem. Assim, o estudo sobre a dicotomia público/privado possibilita a compreensão das transformações diacrónicas, espaciais e sociais, embora seja ilusório tentar traçar uma história contínua do privado e de um binómio de carácter dúbio e controverso. Conforme sublinha Mattoso, apesar da dificuldade que existe na definição e interpretação da linha que separa os dois domínios, os papéis dos homens e das mulheres, dos casados e dos solteiros, dos velhos e dos novos, dos jovens e das crianças, bem como os seus valores e os seus objectivos, alteram-se com o tempo e são distintos conforme as regiões consideradas (Cf. Mattoso, 2011: 13). Se, por um lado, estudar a vida privada implica averiguar a autonomia que the é deixada pelo Estado, pelo poder e pela lei enquanto autoridades que regem a vida pública, por outro lado, o estudo da vida privada não pode ignorar as convenções e as regras tácitas e manifestas que os indivíduos e os seus círculos de 
relacionamento adoptam. Porém, definir a linha que separa o público do privado é, muitas vezes, uma tarefa bastante difícil.

Não obstante o carácter mutuamente exclusivo das esferas, "o sentido das mesmas acções pode ser extremamente ambíguo, conforme os actores envolvidos, o quadro em que se praticam ou as sociedades e grupos que as adoptam" (Mattoso, idem: 14). Deste modo, os contornos da privacidade e da publicidade manifestam-se na vida dos indivíduos segundo as regras que estes impõem a si próprios e de acordo com as convenções da sociedade onde estão inseridos, convenções e hábitos que, consciente ou inconscientemente, os indivíduos aceitam ou transgridem. Todavia, não devemos esquecer que modalidades que contemporaneamente se apresentam como privadas poderiam não o ser nas épocas anteriores. Segundo os historiadores, o uso do conceito de vida privada aplicado às sociedades prévias ao desenvolvimento do Estado Moderno deve ser relativizado e acompanhado de precauções, até porque as informações acerca do comportamento privado dos indivíduos são escassas até ao século XII e difíceis de discernir nos séculos subsequentes. Apesar de na Idade Média se terem dado passos significativos na afirmação da esfera pessoal dos indivíduos, é difícil considerar que o conceito de vida privada, tal como hoje o entendemos, tenha existido naquele período histórico. Uma vez que a escrita medieval foi, durante muito tempo, monopólio da Igreja, as fontes disponíveis apelam constantemente a um ideal de ordem pública de acordo com o modelo que a Cristandade supõe. Neste sentido, aquilo que se passava na vida doméstica deveria ser secreto, pertencendo ao chefe de família a obrigação de zelar pelo cumprimento das normas no espaço privado (Cf. Mattoso, idem: 18-19). Os pecados cometidos na vida privada não deveriam ser públicos no sentido de evitar a sua propagação, mantendo-se a actividade do confessor como algo pertencente à área do privado. De entre tudo aquilo que a família burguesa tinha de privado, o que segundo os historiadores era bastante pouco, o "assentamento" assume peculiar destaque. 0 assentamento consistia no local onde a família rural "assentara" a sua habitação, as terras de cultivo e outros espaços pertencentes à exploração agrícola. A habitação ou "cozinha", como muitas vezes era denominada, era um edifício unicelular, bastante pequeno e com uma só abertura para o exterior. A casa era escura, pequena e sem espaço para o conforto. Junto da habitação estavam os edifícios que serviam de abrigo aos animais (pocilgas, currais...), e outras dependências como os lagares, a adega e os celeiros ou palheiros (Cf. Mattoso, 2011: 39-41).

Já no que se refere ao conceito de público, os textos medievais associam-no directamente ao espaço público urbano materializado nos caminhos, ruas, praças e alguns equipamentos ou infra-estruturas que estão ao dispor da comunidade e que por ela podem ser utilizados. Usualmente, a denominação de público reservavase às vias centrais e de maior importância, sendo normal encontrar alguns espaços públicos privatizados nominalmente. De referir que na época a atribuição do nome de um indivíduo a uma rua não correspondia, como acontece actualmente, a um reconhecimento público ou a uma consagração comunitária de um determinado indivíduo, sendo o nome e o domínio critérios de identificação de áreas privatizadas (Cf, Idem: 26-27). A oposição público / privado no espaço urbano medieval também se encontrava patente no domínio 
dos indivíduos sobre bens patrimoniais. O sistema jurídico e as autoridades públicas garantiam o respeito pela propriedade familiar inscrita no espaço público urbano. Do ponto de vista jurídico, a delimitação entre o público e o privado era nítida e a intrusão alheia no espaço doméstico chegava a configurar a prática de crime. Por outro lado, privadas eram, também, as áreas apartadas ou isoladas da comunidade. Por decisão das autoridades públicas, em redor das áreas urbanas encontravam-se pequenos enclaves que, para protecção da comunidade, alojavam comunidades religiosas minoritárias, como mouros ou judeus. As mulheres que se dedicavam à prostituição, denominadas de "mulheres públicas" ou "mundanais", que "faziam pelos homens" ou "galegas", como eram denominadas em Alcácer do Sal, deveriam habitar em "lugar próprio e apartado onde os homens as procurem e não em vizinhança com mulheres de bom porte" (Idem: 31). A divisão público / privado em termos de sociabilidade, de vivência e de tendência para preservar a vida íntima é, no entanto, mais difícil de discernir no quadro da Idade Média. A preocupação individual com a reserva e preservação da intimidade era algo pontual, até porque a vivência de práticas íntimas não se restringia, em exclusivo, aos espaços habitacionais. As privadas comunitárias, os banhos e as estalagens, correspondiam a edificações mandadas erigir pelos poderes públicos que albergavam práticas íntimas.

Os banhos e as instalações balneares eram, normalmente, propriedades régias exploradas por rendeiros, ao passo que as estalagens, exploradas por "homens ou mulheres que dão camas", funcionavam como locais de hospedagem para forasteiros. Privados eram, também, actos, crimes ou pecados cometidos que não deveriam de ser publicitados para não contaminar a ordem pública. O privado desvelava-se no domínio público sob a fórmula incontornável do rumor e do escândalo.

Efectivamente, público e privado constituem-se como domínios porosos e instáveis que sofreram profundas variações ao longo dos tempos. No decurso dos séculos XVIII e XIX, a vida privada desenvolveu-se como um fenómeno essencialmente burguês onde se assiste a uma forte investida do indivíduo. O Estado liberal assumiu uma matriz individualista que se pautou pela exploração do Eu e pelo reforço da identidade pessoal e de certos cuidados com a aparência. Consequentemente, o conceito de espaço privado renovou-se e passou a ser balizado por novos marcos jurídico-políticos. O círculo familiar surgiu como esfera de intimidade pessoal num contexto onde certos comportamentos privados se democratizaram. Neste ponto, saliente-se a difusão do movimento jornalístico, acompanhado pela prática cada vez mais divulgada da leitura solitária do jornal, a expansão da fotografia e a democratização do retrato pessoal. De outro modo, a casa assumiu-se como domínio privado por excelência, como uma espécie de refúgio onde o indivíduo experimenta o sentimento de independência face à vida pública. Sob o impulso da burguesia, a vida privada foi, no decurso do século XVIII, incorporada definitivamente na ideologia política e societal. 


\section{A democratização da intimidade}

Uma asserção decorrente do percurso histórico-teórico empreendido até aqui passa pela constatação de que nos últimos séculos as concepções de público e privado (re)configuram-se por via da própria dinâmica das estruturas sociais. Aquilo que se convencionou ao longo dos séculos como público ou como privado emerge com uma forte componente histórica, social e política. Neste xadrez sociopolítico, o actor social foi sempre uma espécie de "variável menor". Com esta asserção salienta-se o papel fortemente condicionador das diferentes estruturas sociais, como são os casos da religião, da família e até o papel das elites (em cada contexto histórico particular), que limitaram e conduziram o percurso e as escolhas dos indivíduos, competindo aos actores concretizarem, na durée quotidiana, a forte coerção e controlo social que Émile Durkheim (1977) denominou por solidariedade mecânica.

Contudo, é com o advento da Modernidade que autores como Habermas (2012) assinalam uma profunda reconfiguração social, política e económica. Uma tal mudança com implicações tão transversais levou a um substancial reequilíbrio social, mormente com o fim daquilo que é designado na historiografia como Antigo Regime, abrindo espaço à estruturação das sociedades através das classes sociais. O supra mencionado autor alemão sintetiza este processo da seguinte forma:

"A esfera pública burguesa desenvolve-se no campo de tensão entre o Estado e a sociedade, mas de tal forma que ela própria continua a fazer parte do âmbito privado. A separação fundamental entre essas duas esferas, que ela tem por base, começa por significar o desentrosamento dos momentos de reprodução social e de poder político mantidos juntos nas formas de dominação da Alta Idade Média" (Habermas, 2012: 257 itálico dos autores).

Com esta perspectiva, Habermas tem a intenção de sublinhar o facto de ser no seio de um contexto fortemente pautado pela ordem económica, nomeadamente com a ascensão de uma nova classe, que estas transformações ocorrem. Esta nova classe brotava a partir da dinamização do comércio e assumiu uma posição intermédia entre o chamado "povo" ou classe popular e a "velha" aristocracia com todos os seus privilégios, conjuntamente com algum do clero. Ora, esta nova classe tinha o ensejo de se tornar um actor activo no xadrez político das sociedades modernas, o que implicou uma redefinição da fronteira entre Estado e Sociedade. Com efeito, o que emana deste processo historicamente demarcado é fundamentalmente o facto de haver uma crescente dissociação de uma parte da actividade social do próprio domínio do Estado, que granjeava uma componente considerável da vida social e pessoal quotidiana. Como é referido por Habermas (2012: 257 e seguintes), o privado surge como um espaço dissociado da influência do Estado. Compete aos actores e sobretudo ao seio familiar a "cristalização" de práticas quotidianas que anteriormente eram eminentemente de carácter público. O privado configura-se, assim, como o negativo numa película de filme, no fundo é o outro lado do espaço público. 
Retomando a discussão acerca da emergência e separação entre público e privado, resultado do percurso até aqui empreendido, o privado e as actividades nele desenvolvidas circunscreviam-se, no decurso do século XVIII, fundamentalmente ao quarto. O quarto de dormir era concebido como o derradeiro domínio privado, já que todos os outros espaços, incluindo os do domicílio, eram tidos como de vivência pública. Este é, paralelamente, um período histórico onde, apesar das fortes mutações políticas e económicas, estas não se repercutiram no incremento do papel da mulher e de outros grupos sociais minoritários no debate público. A dicotomia público / privado passava, também, pela diferença de género, sendo a esfera pública o espaço privilegiado do homem e o privado ou o doméstico o espaço de acção da mulher. 0 discurso oitocentista insiste nas qualidades e aptidões do homem e da mulher como base das duas esferas: aos homens, o cérebro e a capacidade de decisão; às mulheres, o coração, a emoção e os sentimentos.

Efectivamente, o estudo do público e do privado, sobretudo do segundo, deve-se à democratização da intimidade, processo desencadeado nas sociedades da modernidade tardia, pelo menos na perspectiva de Anthony Giddens (1995). O argumento que Giddens concebe como "pano de fundo" para a sua exposição, centra-se no facto de embora a esfera privada surgir de "mão dada" com o advento da burguesia enquanto classe social no final do Antigo Regime, é nas sociedades contemporâneas que se verifica uma verdadeira democratização da intimidade. Não será por acaso que só é possível reequacionar o papel da intimidade associando a esta a própria vivência e consolidação do regime democrático. Contudo, antes de continuarmos a discussão importa esclarecer que a intimidade deve ser entendida como um conjunto "(...) de direitos e obrigações, prerrogativas e responsabilidades que norteiam modelos de actividade e prática quotidiana" (1995: 131). Por outro lado, a umbicalidade entre democracia e intimidade fica patente se considerados alguns dos seguintes aspectos: em primeiro lugar, a criação de circunstâncias em que as pessoas possam desenvolver as suas potencialidades e exprimir as suas diferentes qualidades; em segundo, a proteç̧ão do uso arbitrário da autoridade política havendo lugar à negociação; em terceiro lugar, a aceitação dos juízos de valor dos outros e, por fim, a liberdade económica e de acção (1995).

A prossecução em maior ou menor escala destes aspectos apenas ficou minimamente garantida, pelo menos no contexto das sociedades ocidentais, em meados do século XX, sobretudo após o termo da II Guerra Mundial. Contudo, no Mediterrâneo e em particular em Portugal, o processo histórico-político assume contornos idiossincráticos. 0 processo de democratização da sociedade portuguesa encetado a 25 de Abril 1974 tem progressivamente levado à definição jurídica de certas liberdades, como a possibilidade do divórcio mediante iniciativa unilateral de uma das partes, ou, mais recentemente, a despenalização da interrupção voluntária da gravidez (referendo de 2007), ou o casamento entre pessoas do mesmo sexo por iniciativa legislativa/parlamentar em 2010. Estes são casos que ilustram a estreita relação entre a democraticidade de uma sociedade e a consolidação e profusão daquilo que geralmente se convencionou como intimidade. Com efeito, estamos no patamar de discussão do poder condicionador das grandes estruturas sociais, relativamente à acção social de cada actor. 
É, precisamente, no plano da subjectividade individual que encontramos uma profunda disrupção das sociedades da modernidade tardia relativamente às suas predecessoras. Nesta linha, são diversos os elementos que nos fornecem pistas da crescente relevância da capacidade de escolha por parte dos indivíduos, resultando em planos biográficos de carácter mais aberto e de negociação permanente. Podemos encontrar nas últimas décadas de empreendimento das ciências sociais um conjunto de autores como Beck (2000; 2006), Giddens e Lash (2000), Bourdieu (1989; 2010) e Bauman (2007) onde se nota uma clara tendência de realizar uma síntese entre poder condicionador das estruturas sociais e a capacidade de agir dos actores. Também no plano do estudo das atitudes, como em Inglehart (2005), é identificado o crescente carácter individual e expressivo em termos geracionais, com a já famosa transição dos valores materialistas para pós-materialistas.

Transversalmente, todos estes autores sublinham a preponderância epistemológica e teórica das competências cognitivas e sociais dos indivíduos na negociação quotidiana. Os actores num contexto estruturalmente mais democrático podem accionar um conjunto diversificado de competências e mecanismos conquistando, ainda que em permanente tensão com a normatividade social vigente, um espaço de autonomia que de acordo com Anthony Giddens pode ser definido como "(...) a capacidade individual para a auto-reflexão e para a autodeterminação: "deliberar, julgar, escolher e agir de acordo com possíveis rumos de acção" (1995: 128 aspas do original).

Esta crescente autonomização está associada a um processo histórico que passa pela individualização (Beck: 210-211). Segundo Beck, este processo assenta em três grandes domínios: perda da estabilidade, perda da segurança tradicional e um novo tipo de coesão social. A individualização, enquanto modelo de socialização de actores, resulta sobretudo numa maior liberdade de aç̧ão, mas paralelamente de menor segurança societal. No seu empreendimento teórico, Ulrich Beck (2003) reconhece uma espécie de descontinuidade entre aquilo que convencionalmente se designa como modernidade e modernidade reflexiva, mormente no que concerne aos modos e estilos de vida. Para o autor alemão, estas alterações ficam-se a dever, em parte, a transformações no campo dos principais eixos identitários, como a classe social, o género ou até a etnia, entre outros elementos. Deste modo, antagonicamente ao que se perspectivava um pouco por toda a classe científica, a emergência da modernidade reflexiva não trouxe consigo uma uniformização cultural. Pelo contrário, de certa forma podemos até falar de uma destandardização das biografias individuais.

Nesta linha de raciocínio, torna-se clara a tendência para a crescente multiplicação e diversificação das opções biográficas dos indivíduos, aquilo que se pode definir como uma espécie de bricolage-identitária. 0 que leva Beck (2003) a falar de uma crescente cultura do eu patente no cada vez maior número de indivíduos a viver sozinhos, tal como o aumento de número de divórcios e, também, o fomento de estilos de vida estéticos ou ainda a consciência e prática de uma maior liberdade e, consequentemente, de uma maior auto-organização orientada para acção. 
Dito isto, a esfera íntima surge na contemporaneidade como um importante domínio de análise de diversos autores. Neste rol, Anthony Giddens (1994 e 1995) localiza naquilo a que resolve definir como relação pura uma marca da democratização da intimidade, nomeadamente no seio familiar e dos afectos. Há, assim, lugar à reconfiguração das estruturas sociais que servem de mapeadores na gestão que os actores fazem das suas relações pessoais e íntimas e à multiplicação e diversificação de modelos biográficos, sendo que nem todos os modelos podem ser sinónimo de mais bem-estar podendo resultar, e em última análise, em difíceis escolhas. Um caso paradigmático é o da família enquanto instituição social. Diríamos que actualmente há a possibilidade de a mulher ter uma carreira profissional, que lhe permite aceder a uma autonomia financeira, a qual foi restringida em gerações anteriores. Contudo, esta opção implica muitas vezes o sacrifício da maternidade, em casos extremos. Nestas circunstâncias, e de acordo com Bauman (2007: 205), podemos considerar a individualização como um processo ambivalente, ou por outras palavras, se por um lado abre novas possibilidades de escolha, por via da descontextualização das relações sociais, por outro lado, levanta novos dilemas traduzíveis em constrangimentos, sobretudo na esfera da intimidade.

Zygmunt Bauman na sua abordagem às mutações ocorridas nas esferas pública e privada, coloca na equação analítica que ensaia o caso dos media e o papel que estes têm tido nas últimas décadas na erosão entre estes dois domínios. Para Bauman (2002: 75), os chat-shows, onde podemos incluir o Facebook, têm um grande potencial de divulgação e publicitação de considerações e expressões íntimas. Ainda assim, a questão que se impõe é saber quais as motivações para essa exposição. O supramencionado autor começa por aduzir que nas sociedades contemporâneas há uma incessante necessidade de aprovação e diversão relativamente ao meio envolvente. No fundo, assiste-se à exposição orgulhosa do individual, do emocional e do secreto enquanto categorias que permaneciam, até aqui, na esfera íntima.

No plano ético e relacional, este fenómeno apresenta implicações relevantes como, por exemplo, um progressivo mitigar de constrangimentos relacionados com a vergonha e a humilhação, sentimentos que até aqui tinha no domínio da intimidade o seu derradeiro reduto. Existe, com efeito, uma constante procura de uma espécie de "redenção social". É nesta linha de raciocínio que Bauman (2002: 75) opta por designar como o "consolo pela absolvição", um consolo que passa, fundamentalmente, pela exposição de sentimentos e afectos que outrora pertenciam exclusivamente à intimidade, à privacidade. Com efeito, podemos apontar duas importantes características da esfera íntima nas sociedades contemporâneas: a expressionista e a impressionista. Aliás, com isto, não estamos a negar a possibilidade de estas fazerem parte da vivência intima. O que queremos enfatizar é o facto de estas saírem reforçadas e exacerbadas, sobretudo como resultado do processo de individualização, isto é, são eixos que norteiam a gestão e exposição dos afectos. Ora, atentando à componente expressiva da intimidade nas sociedades contemporâneas, antagonicamente ao que se passava até aqui, a manifestação de afectos faz-se privilegiadamente por via dos media, mormente media sociais como o Facebook (Carvalheiro, Prior, Morais, 2013: 109-113). Esta plataforma digital, com a sua arquitetura de divulgação (Marichal, 2012), transmite aos seus utilizadores uma sensação de segurança associada à liberdade 
de acção e de poder de decisão individual no que se refere aos elementos de exposição. Por outro lado, na linha do que temos vindo a afirmar, estão reunidas as condições estruturais para que os actores ajam de forma livre, ainda que reflexivamente ponderando as suas vantagens e desvantagens, resultado naquilo a que Beck (2003: 339-355) designou por "instituições zombies".

Deste modo, o actor fica mais liberto para agir de forma a mitigar os efeitos constrangedores da normatividade vigente, até porque essa mesma normatividade o remete para o campo da decisão individual e reflexiva. Este processo é aplicável a práticas de exposição e representação, sobretudo quando estas estão à distância da observação e da visibilidade inerentes ao espaço digital e, em particular, às redes sociais que enfatizam a opticização das particularidades e das experiências subjectivas dos indivíduos. A propósito, Daniel Innerarity tece a seguinte constatação:

"Numa sociedade articulada em redor dos meios de comunicação, a distinção fundamental é entre a atenção e a ignorância; tudo se decide na capacidade de perceber e ser percebido. Não há nada pior que passar despercebido, ser invisível. A própria existência parece incerta enquanto não é confirmada pelo olhar de outros" (2009: 134).

No fundo, trata-se da exaltação da singularidade individual, uma exaltação que concebe cada vez mais relevo aos aspectos privados da existência e à enunciação da visibilidade identitária e de afectos e vivências pessoais. Como tivemos oportunidade de constatar, a preocupação que os indivíduos sentem em se exteriorizar é uma influência da civilização helenística, mas parece evidente que este sentimento regressou mediante novas formas de exteriorização que, no entanto, mais não fazem do que acentuar a tendência secular da sociedade como esfera de aparição, como espaço de ser e de aparecer para os outros. $O$ incremento das tecnologias de informação, especificamente das redes sociais digitais, intensificou a categoria da aparência presente nas interacções quotidianas onde os indivíduos representam o seu self. Porém, e tal como sublinhou Joshua Meyrowitz (1986), a natureza dos media electrónicos torna bastante difícil separar a esfera das experiências públicas da esfera das experiência privadas, anulando-se, consequentemente, a distinção goffmaniana entre bastidores e palco e entre público e privado.

\section{Referências Bibliográficas}

Arendt, Hannah (2001). A Condição Humana. Lisboa: Relógio D'Água (Obra originalmente publicada 1958). Ariès, Philippe, Duby, Georges (1989). História da Vida Privada: do Império romano ao ano mil, Vol. 1. Porto: Afrontamento (Obra originalmente publicada 1983).

Bauman, Zygmunt (2002). Modernidad Liquida. (M. Rosenberg Trad.). Buenos Aires: Fondo de Cultura Económica de Argentina (Obra originalmente publicada 2000). 
Bauman, Zygmunt (2007). Modernidade e Ambivalência (M. Penchel Trad.). Lisboa: Relógio d'Água Editores (Obra originalmente publica em 1991).

Beck, Ulrich; Giddens, Anthony \& Lash, Scott (2000). Modernização Reflexiva: politica, tradição, e estética no mundo moderno (M. A. Augusto Trad.). Oeiras: Celta Editora (Obra originalmente publicada em 1994).

Beck, Ulrich (2000). "A reinvenção da política". in Ulrich Beck; Anthony Giddens \& Scott Lash, (Orgs.). Modernização Reflexiva: política, tradição, e estética no mundo moderno (pp. 1-51). Oeiras: Celta Editora (Obra originalmente publicada em 1994).

Beck, Ulrich (2003). La Individualización. El individualismo institucionalizado y sus consecuencias sociales y políticas (B. MorenoTrad.). Barcelona: Edicones Paidós Ibérica (Obra originalmente publicada 2002).

Beck, Ulrich (2006). La Sociedad del Riesgo Hacia una Nueva Modernidad (J. Navarro; D. Jiménez \& M. R. Borrás Trad.). Paidós Surcos 25: Barcelona (Obra originalmente publicada em 1986).

Bobbio, Norberto (2009). Estado, Governo e Sociedade: para uma teoria geral da política. Rio de Janeiro: Paz e Terra (Obra originalmente publicada em 2006).

Bourdieu, Pierre (1989). O poder Simbólico (2a Edição) (F. Portugal Trad.). Lisboa: Difel Difusão Editorial Lda (Obra originalmente publicada 1977).

Bourdieu, Pierre (2010). A Distinção. Uma Critica Social da Faculdade do Juízo (P. E. Duarte Trad.) Lisboa: Edições 70 (Obra originalmente publicada 1979).

Carvalheiro, José Ricardo, Prior, Hélder, Morais, Ricardo (2013). "Público, Privado e representação online: 0 caso do Facebook" in António Fidalgo, João Canavilhas (Org), Comunicação Digital-10 anos de Investigação, Coimbra, MinervaCoimbra Edições.

Durkheim, Émile (1977). A Divisão Social do Trabalho (M. I. Mansinho \& E. Freitas Trad.) Lisboa: Editorial Presença (Obra originalmente publicada 1893).

Esteves, João Pissarra, Público/Privado, Dicionário de Filosofia Moral e Política, Instituto de Filosofia da Linguagem.Disponível: http://www.ifl.pt/private/admin/ficheiros/uploads/4cd129f920df65b36c0c8672cb86dbfd.pdf

Giddens, Anthony (1994). Modernidade e Identidade Pessoal (M.V. Almeida Trad.). Oeiras: Celta Editora (Obra originalmente publicada 1991).

Giddens, Anthony (1995). Transformações da Intimidade. Oeiras: Celta Editora (Obra originalmente publicada 1992).

Giddens, Anthony (2000). Dualidade da Estrutura: Agência e Estrutura. Oeiras: Celta Editora (Obra originalmente publicada 1979).

Giddens, Anthony (2005). As Consequências da Modernidade (4aEdição) (F. L. Machado \& M. M. Rocha Trad.). Oeiras: Celta Editora (Obra originalmente publicada 1990). 
Goffman, Erving (1993). A Apresentação do eu na Vida de Todos os Dias (M. S. Pereira Trad.). Lisboa: Relógio D’Água Editores (Obra originalmente publicada 1959).

Habermas, Jürgen (2012). A Transformação Estrutural da Esfera Pública (L. Nahodil Trad.). Lisboa: Fundação Calouste Gulbenkian (Obra originalmente publicada 1961).

Inglehart, Ronald \& Wezel, Christian (2005). Modernization Cultural Change, and Democraç: The Human Developmen Sequence. Cambridge: University Press.

Innerarity, Daniel (2009). A Sociedade Invisivel (M. Ruas Trad.). Lisboa: Teorema (Obra originalmente publicada 2004).

Kant, Immanuel (2004) "Que é o Iluminismo?" in A Paz Perpétua e outros opúsculos, Lisboa, Edições 70 (Obra originalmente publicada 1784).

Luhmann, Niklas (1992). A Improbabilidade da Comunicação. Lisboa: Veja (Obra originalmente publicada 1981).

Marichal, José (2012). Facebook Democracy. The Architecture of Disclosure and the Threat to Public Life. Burlington: Ashgate Publishing Company.

Mateus, Samuel (2011). Publicidade e Consumação nas Sociedades Contemporâneas, Covilhã: Livros LabCom.

Mattoso, José (2011). História da vida privada em Portugal: a Idade Média, Vol. 1. Lisboa: Círculo de Leitores, Temas e Debates.

Mattoso, José (2010/2011). História da vida privada em Portugal: a idade Moderna, Vol. 2. Lisboa: Círculo de Leitores, Temas e Debates.

Mattoso, José (2010/2011). História da vida privada em Portugal: a época Contemporânea, Vol. 3. Lisboa: Círculo de Leitores, Temas e Debates.

Meinecke, Friedrich (1983). La idea de la Razón de Estado en la Edad Moderna. Madrid: Centro de Estudios Constitucionales (Obra originalmente publicada 1924).

Meyrowitz, Joshua (1986). No sense of place: The Impact of Electronic Media on Social Behaviour. New York: Oxford University.

Rodrigues, Adriano D., O Público e o Privado. Disponível em: http://www.bocc.ubi.pt/pag/rodriques-adrianopublico-privado.pdf.

Senellart, M. (1995). Les arts de gouverner, Du regímen médiéval au concept de gouvernment. Paris: Éditions du Seuil.

Silva, Filipe C. (2002). Espaço Público em Habermas. Lisboa: Imprensa de Ciências Sociais - ICS.

Zarka, Yves C. (1994). Raison et Déraison d'État. Paris: Presses Universitaires de France. 